\title{
A NEW GEOMETRIC INTERSECTION POINT (MS) TO DETERMINE THE SPATIAL POSITION OF MAXILLARY SINUS
}

\author{
Dr Sarabjeet Singh ${ }^{1}$, Dr Mukti Gautam ${ }^{2}$, Dr Rita Kashyap ${ }^{3}$, Dr Gurinderpal Sandhu ${ }^{4}$, Dr Divya Singla ${ }^{5}$ \\ ${ }^{1}$ Prof. \& Head, Department of Orthodontics and Dentofacial Orthopedics, Bhojia Dental College \& Hospital, Distt. Solan, Himachal \\ Pradesh (India) \\ ${ }^{2}$ PG Student, Department of Orthodontics and Dentofacial Orthopedics, Bhojia Dental College \& Hospital, Distt. Solan, Himachal \\ Pradesh (India) \\ ${ }^{3}$ Sr. Lecturer, Department of Orthodontics and Dentofacial Orthopedics, Bhojia Dental College \& Hospital, Distt. Solan, Himachal \\ Pradesh (India) \\ ${ }^{4}$ Reader, Department of Orthodontics and Dentofacial Orthopedics, Bhojia Dental College \& Hospital, Distt. Solan, Himachal Pradesh \\ (India) \\ ${ }^{5}$ Sr. Lecturer, Department of Orthodontics and Dentofacial Orthopedics, Bhojia Dental College \& Hospital, Distt. Solan, Himachal \\ Pradesh (India) \\ Corresponding Author: \\ ${ }^{1}$ Mobile: 919876061283 Email: sarabjeet3400@yahoo.co.in
}

\begin{abstract}
Received :

$19^{\text {th }}$ May, 2013

Accepted:

$13^{\text {th }}$ August, 2013

Available online:

$25^{\text {th }}$ August, 2013

Introduction: Cephalometeric landmark detection, is a knowledge intensive activity to identify on standardized lateral x-rays of the skull, to perform measurements needed for medical diagnosis, treatment planning and evaluation. For computation of analysis of steps and for determination of underlying structures, provided landmarks should be correctly localized. Due to the complexity of human anatomy sensed in a cephalometric x-ray, the landmarks are localized and constructed. Maxillary sinus has an important role to play in the formation of facial contours. Objective: Our aim is to check the validity of new geometric intersection point Ms, evaluating cephalometerically the spatial position of maxillary sinus and to find any correlation between the spatial position of maxillary sinus and sagittal dysplasias. Study design: A single-institution prospective analysis. Subjects and methods: A total of 20 lateral cephalograms were used, of both sexes, ranging in age from 18-25 years. These radiographs were from subjects, classified into class I and class II on the bases of ANB and Ao-Bo. Maxillary sinus was carefully analyzed and measured in linear dimensions of length and width and its spatial position was calculated by using a new geometric intersection point $\mathbf{M}_{\mathbf{s}}$, created by the intersection of the linear measurements, in relation to the anterior cranial base. The spatial position of maxillary sinus was calculated from the position of the intersection point Ms. The length and height of maxillary sinus was measured and compared in both the groups. Results: The mean of maxillary sinus length (MSL) and height (MSH) was $43.2 \pm$ SD $3.2 \mathrm{~mm}$ and $41.2 \pm \mathrm{SD} 3.8 \mathrm{~mm}$, respectively for classI (p value=0.595) and $44.2 \pm \mathrm{SD} 4.9 \mathrm{~mm}$ and $43.0 \pm \mathrm{SD} 3.4 \mathrm{~mm}$, respectively for class II ( $\mathrm{p}$ value $=0.283$ ). The intersection point Ms depicting centre of maxillary sinus from x-axis (Ms-Msx) was same for both the groups. Mean for Ms-Msy, was 37.3 \pm SD 5.7 for class I and $37.8 \pm$ SD 1.9 for class II (p value=0.796). No statistical significance was found among the results in both the groups. Conclusion: The length and height of maxillary sinus was calculated and the centre of maxillary sinus was calculated by the intersection of the two. This new point can contribute in calculating the spatial position of sinus and be an effective measure to study the convexity and concavity of the midface. In the present study, the length and height of the sinus did not alter with the increased or decreased ANB and Ao-Bo. There was no significant spatial position change of maxillary sinus with variation in ANB and Ao-Bo (sagittal). Regarding vertical parameters, Ms may have significant correlation with the various malocclusions.
\end{abstract}

Keywords: Maxillary sinus, Anatomic landmarks, Malocclusion

\section{INTRODUCTION}

The bony chambers embedded into the bones around the nasal cavity and opening into the nasal cavity are called "paranasal sinuses". Of these, the maxillary sinuses in the maxilla are the largest of the paranasal sinuses. ${ }^{1}$ It arises from the middle meatus at the beginning of the foetal period, but most expansion develops after birth with the development of the middle third of the face and eruption of the secondary dentition. ${ }^{2}$ Thus, it has an important role to play in the formation of facial contours. The inferior growth of maxillary sinus is related to its invasion of the alveolar process following the eruption of permanent teeth, thus extending $4-5 \mathrm{~mm}$ inferior to the nasal floor. ${ }^{3}$ This may influence orthodontic plan for 
malocclusion cases. The absence of the maxillary first molars over a long period of time may make the maxillary sinus invade the alveolar process of the missing site more inferiorly, thus impeding the protrusion of the maxillary second molars as the result of the contact of the cortical bone of the maxillary sinus floor with their roots. The use of mini-implant as an absolute molar anchorage unit is placed in the inter-dental area between the maxillary second premolars and the first molars. The morphological evaluation of the sinus is necessary to deal with the problems such as injury to the tooth roots and perforation of the sinus during the procedures. Studies have shown reformation of maxillary sinus during maxillary suture expansion. ${ }^{4}$ In patients with cleft lip and palate, some reports regarding the development and size of maxillary sinus have been published with varying results. ${ }^{5}$

The procedures for measuring maxillary sinus used till today have been done by using cadaveric skulls, dry skulls, panoramic radiographs, computed tomography images and magnetic resonance imaging scans. In orthodontic dentistry, cephalograms have been most commonly used as they permit total visualisation of maxillary sinus size (Figure $1 \& 2$ ). It could be hypothesised that the development of maxillary sinuses, which have close relationship with the maxilla and the upper posterior teeth, might be affected by dental and skeletal malocclusion. Yet very few cephalometeric studies on association of maxillary sinus size with malocclusion have been found. ${ }^{1,2}$

Thus, the aim of the present study is:

a) To check the validity of new geometric intersection point Ms, evaluating cephalometerically the spatial position of maxillary sinus.

b) To find any correlation between the spatial position of maxillary sinus and sagittal dysplasias.

\section{MATERIALS AND METHOD}

This prospective study was carried out in the department of Orthodontics and DentofacialOrthopaedics. A complete history and examination of all the subjects was done prior to their inclusion in the study. 20 cephalograms were chosen on the basis
ANB and AO-BO. The following inclusion and exclusion criteria will be followed in the study.

\section{INCLUSION CRITERIA}

- Fully erupted permanent dentition.

- Subjects aged between 18-23 years.

\section{EXCLUSION CRITERIA}

- No tooth agenesis or extraction.

- No maxillary sinus pathology.

- No craniofacial anomaly.

- No facial asymmetry.

- No previous orthodontic treatment.

- No history of trauma.

- $\mathrm{ANB}<0^{0}$ and Ao-Bo $<-2 \mathrm{~mm}$.

Subjects were divided into two groups on the basis of $:(\mathrm{n}=20)$

1. Class $\mathrm{I}-\mathrm{ANB} 0-3^{0}$ and Ao-Bo-2 - $+2 \mathrm{~mm}$ $(n=10)$

2. Class II $-\mathrm{ANB}>3^{0}$ and Ao-Bo $>2 \mathrm{~mm}$ $(n=10)$

During the exposure of cephalograms, the subjects were guided to stand still to ensure that no strain or change in head posture occurred while the head is fixed in the cephalostat. All lateral cephalograms were exposed in the same cephalostat with similar exposure parameters and standardized settings. Lateral cephalograms of the subjects were traced and investigated by a single investigator. The tracings were done on the left side. Landmarks and planes, selected and marked for the evaluation of maxillary sinus size and dentofacial morphology, are mentioned below, and rectangular coordinates were manually drawn on each sheet of tracing paper. The rectangular coordinates, with the $x$ axis parallel to the Frankfurt horizontal plane (Pr-Or) and the $y$ axis perpendicular to the Frankfurt horizontal plane through the sella, were used for maxillary sinus measurements. The sagittal discrepancy was measured by using ANB (Steiner's) and Ao-Bo (Wit's appraisal). 


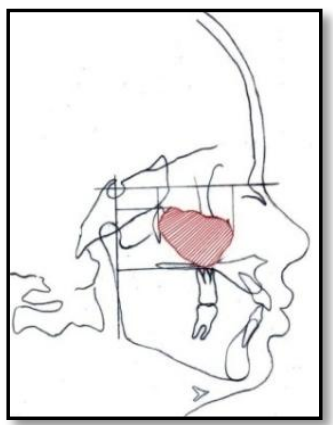

Figure 1

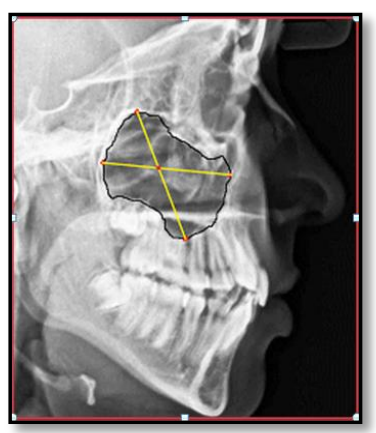

Figure 2

\section{LANDMARKS AND PLANES (Figure 3)}

1. Nasion $(\mathrm{N})$ : intersection of internasal suture with nasofrontal suture in mid sagittal plane.

2. Sella turcica $(S)$ : midpoint of sella turcica.

3. Point A (A) : deepest midline point on premaxilla between anterior nasal spine and prosthion.

4. Point B (B) : most posterior point in concavity between infradentale and pogonion.

5. Orbitale (Or) : lowest point on lower margin on bony orbit.

6. Porion (Po) : midpoint on upper edge of porus austicus externus. ${ }^{6}$

7. Point An (An) : most anterior point of maxillary sinus.

8. Point An' (An') : point projected vertically from An to the $x$ axis.

9. Point $\mathrm{Po}(\mathrm{Po})$ : most posterior point of maxillary sinus.

10. Point Po' (Po') : point projected vertically from Po to $x$ axis.

11. Point $\mathrm{Su}(\mathrm{Su})$ : most superior point of maxillary sinus.

12. Point $\mathrm{Su}^{\prime}\left(\mathrm{Su}^{\prime}\right)$ : point projected vertically from Su to $y$ axis.

13. Point In (In) : most inferior point of maxillary sinus.

14. Point In' (In') : point projected vertically from In to the $y$ axis.

15. Point Ms (Ms) : point formed by intersection of the two lines joining An-Po and Su-In ,giving the centre of maxillary sinus.

16. Point $\mathrm{Ms}_{\mathrm{x}}$ : point projected vertically from Ms to the $x$ axis.

17. Point $\mathrm{Ms}_{\mathrm{y}}$ : point projected vertically from Ms to the $y$ axis.
18. Point Ao (Ao) : point of contact on occlusal plane, by drawing a perpendicular line from pointA.

19. Point Bo (Bo) : point of contact on occlusal plane, by drawing a perpendicular line from point B

\section{PLANES}

1. S-N plane: plane formed by joining point $\mathrm{S}$ (sella) and point $\mathrm{N}$ (nasion).

2. FH plane : plane formed by joining point $\operatorname{Pr}$ (porion) and point Or(orbitale).

3. Occlusal plane : plane drawn through the region of the overlapping cusps of the first premolars and first molars.

\section{MEASUREMENTS (Figures 3\&4)}

1. $\mathrm{Ms}^{-} \mathrm{Ms}_{\mathrm{x}}(\mathrm{mm})$ : distance between $\mathrm{Ms}$ and $\mathrm{Ms}_{\mathrm{x}}$.

2. $\mathrm{Ms}_{\mathrm{M}} \mathrm{Ms}_{\mathrm{y}}(\mathrm{mm})$ : distance between $\mathrm{Ms}$ and $\mathrm{Ms}_{\mathrm{y}}$.

3. MSL (mm) : distance between Po'-An'.

4. $\operatorname{MSH}(\mathrm{mm})$ : distance between Su'-In'.

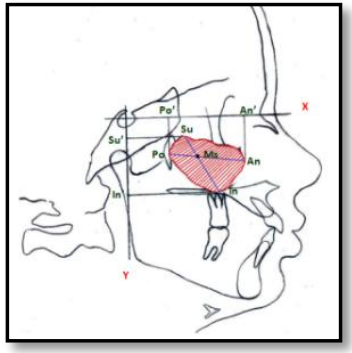

Figure 3



Figure 4
The radiographic images of maxillary sinus were traced on acetate paper. The length of maxillary sinus was calculated by measuring the distance between Po'-An' on the x-axis and height between Su'-In' on the $y$-axis (Figure 3). The centre of maxillary sinus was determined by intersection of lines Po-An and Su-In (Figure 3). The spatial position of maxillary sinus was calculated by measuring the distance between Ms-Msx on the X-axis and Ms-Msy on the yaxis (Figure 4). Statistical analysis was performed and a $\mathrm{p}$ value less than 0.05 was accepted as significant. The Student's t test was used to analyze the maxillary sinus length and height and its spatial position, in both the groups. 


\section{RESULTS}

The values for MSL, MSH, Ms-Msx and Ms-Msy were measured and their means with standard deviations were calculated. In class I group, the mean of MSL was 43.2 \pm 3.2 , MSH 41.2 \pm 3.8 , Ms-Msx 24.5 \pm 3.9 and Ms-Msy 37.3 \pm 5.7 was calculated (Table I). In class II group, the mean of MSL was

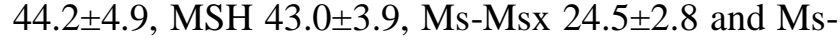
Msy 37.8 \pm 1.9 (Table II).

TABLE I : RESULTS OF MAXILLARY SINUS MEASUREMENTS IN CLASS I GROUP



TABLE II: RESULTS OF MAXILLARY SINUS MEASUREMENTS IN CLASS II GROUP

\begin{tabular}{|c|c|c|c|c|c|c|c|c|}
\hline \multicolumn{3}{|c|}{ Class II } & \multicolumn{4}{|c|}{$\mathrm{ANB}>3^{0}$} & \multicolumn{2}{|c|}{ Ao-Bo > $2 \mathrm{~mm}$} \\
\hline Sno & & MSL & & $\mathrm{MSH}$ & & s-Msx & & Msy \\
\hline 1 & & 47 & & 46 & & 22 & & 39 \\
\hline 2 & & 48 & & 48 & & 30 & & 41 \\
\hline 3 & & 44 & & 42 & & 22 & & 35 \\
\hline 4 & & 33 & & 37 & & 26 & & 36 \\
\hline 5 & & 43 & & 40 & & 21 & & 36 \\
\hline 6 & & 44 & & 40 & & 27 & & 36 \\
\hline 7 & & 42 & & 43 & & 24 & & 39 \\
\hline 8 & & 52 & & 44 & & 22 & & 39 \\
\hline 9 & & 44 & & 47 & & 25 & & 39 \\
\hline 10 & & 45 & & 43 & & 26 & & 38 \\
\hline Mean & 44.2 & SD 4.9 & 43.0 & SD 3.9 & 24.5 & SD 2.8 & 37.8 & SD 1.9 \\
\hline
\end{tabular}

TABLE III: COMPARISON OF CLASS I AND CLASS II AND T-TEST FOR MAXILLARY SINUS MEASUREMENTS

\begin{tabular}{|c|c|c|c|c|c|c|c|}
\hline \multirow{2}{*}{} & \multicolumn{2}{|c|}{ Class 1 } & \multicolumn{2}{c|}{ Class II } & \multirow{2}{*}{$\mathrm{t}$} & \multirow{2}{*}{ df } & \multirow{2}{*}{ p value } \\
\cline { 2 - 5 } & Mean & SD & Mean & SD & & & .595 \\
\hline MSL & 43.2 & 3.2 & 44.2 & 4.9 & -.541 & 18 & .283 \\
\hline MSH & 41.2 & 3.8 & 43.0 & 3.4 & -1.108 & 18 &. \\
\hline Ms Msx & 24.5 & 3.9 & 24.5 & 2.8 & & & \\
\hline Ms-Msy & 37.3 & 5.7 & 37.8 & 1.9 & -.263 & 18 & .796 \\
\hline
\end{tabular}

Table III compares the mean values for the groups and t- test values show no statistical significant difference between the two groups as values show $\mathrm{p}>0.05$. 


\section{DISCUSSION}

The oral cavity and its bony components (maxilla and mandible), along with the nose and its related sinuses, constitute most of the face. The development of the paranasal sinuses, in human race and in many mammals remained as much an enigma as it did nearly two millennia ago. Alterations of the craniofacial morphology during the evolution of the hominids was considered as an important factor affecting the maxillary sinus morphology. ${ }^{3}$ The shape and size and position of the maxillary sinus reflect developments of bony structures of the midfacial area, and they may be associated with determining of the shape of midface. ${ }^{8}$ Thus, it has an important role to play in the formation of facial contours and it could be hypothesised that the development of maxillary sinuses, which have a close relationship with the maxilla and with the upper posterior teeth, might affect the dental or skeletal malocclusion, or vice versa.

Lateral cephalograms have been most commonly used for diagnosis and evaluation of treatment outcome and are routinely used for orthodontic records. Minimum exposure and appropriate cost, apart from easy availability was one of the deciding factors for their use in this study. Moreover, very few cephlometric studies on maxillary sinus were found in literature. Radiographically the sinus is visible at 5 months after birth in a standard antero-posterior view and after dentition sinus only gradually enlarges, reaching its final size to $17-18$ year of life. ${ }^{3}$ Previous studies have shown no significant gender difference in maxillary size measurements. ${ }^{1}$

The maxillary sinus length and height were calculated. These measurements and findings are consistent with Toshiyo Endo et al. ${ }^{2}$ Our results show similar MSL and MSH among the two groups and no statistical significancant values. This tendency can be explained by the fact that larger ANB angle can be due to mandibular deficiency, rather maxillary excess. Moreover inclusions of subjects with skeletal class III parameters might have provided a variable result .

Though the centre of maxillary sinus depicted by a new point Ms, proved to be an effective way to determine the spatial position of sinus in class I and class II groups, yet the spatial position of maxillary sinus in anteroposterior as well as vertical dimensions showed no difference in both the groups. Maxillary sinus, located in the body of maxilla, is the largest of the four paranasal sinuses and contributes midfacial growth and appearance. Alberti reported that a small, narrow maxillary sinus with a concave anterior wall gives rise to a dish face, and that large maxillary sinus with a convex anterior wall gives rise to a rounded face. ${ }^{12}$ Thus, Ms can be a contributing factor in predicting the midfacial contours and associated malocclusions.

Uchida et al reported that the height of the maxillary sinus is the primary determinant of the volume of the sinus; depth is the second most important variable. ${ }^{11}$ Lateral cephalograms permit total visualisation of maxillary sinus, although limitations in using cephalograms because of their two dimensional orientation were encountered. Transverse dimensions of sinus could not be used in lateral cephalograms. The spatial position of maxillary sinus, thus needs to measured by using different parameters, may be that enhance and highlight the height, width and depth of maxillary sinus. The limitations of this study included two dimentional lateral cephalograms, exclusion of vertical parameters and small sample size. $^{10}$ The centre of maxillary sinus Ms, may be effectively used to study various malocclusions in sagittal as well as vertical dysplasias and can be helpful in predicting midface deficiencies and improved profiles.

\section{CONCLUSIONS}

A new cephalometric intersection point Ms, was constructed to determine the spatial position of maxillary sinus in sagittal and vertical dysplasias, which has an important role to play in the formation of facial contours. Further studies would be required to compare and evaluate maxillary sinus complex with various malocclusions for a better diagnosis and treatment planning.

\section{REFERENCES}

1. Husamattin Otkay. The study of maxillary sinus areas in different orthodontic malocclusions. AJO 1992;102:143-5.

2. Toshiya Endo, Ryota Abe, Hiroo Kuroki, Koji Kojima, Kenji Oka, Shohachi Shimooka. Cephalometeric evaluation of maxillary sinus sizes in different malocclusion classes. Odontology 2010;98:65-72. 
3. Scott and Brown. Otorhinolaryngology, Head and Neck Surgery, $7^{\text {th }}$ ed; 2008.

4. Kulbersh PV, Wine P, HaugheyM, Pajtas B, Kaczynski R. Cone beam computed tomography evaluation of changes in the naso-maxillary complex associated with two types of maxillary expanders. Angle Orthod. 2012;82:448-457.

5. Kim HY, Kim MB, Dhong HJ, Jung YG, Min JY et al. Changes of max. sinus volume and bony thickness of the paranasal sinuses in longitudinal pediatric chronic rhinosinusitis. Int. Journal of pediatric otorhinolaryngology 2008 Jan;72(1):103-108

6. Alexander Jacobson. Radiographic cephalometery- From basic to videoimaging, $1^{\text {st }}$ ed. Hongkong: Quintessence publishing co, Inc :1995:117.

7. Efthimia K. Basdra, Angelika Stellzig and Gerda Komposch The importance of maxillary sinus in facial development : a case report. EJO $1998 ; 20: 1-4$.
8. Jean Delaire. Maxillary development revisited: relevance to the orthopaedic treatment of the class III malocclusions. EJO 1997;19:289-311.

9. Seok Hyun Cho, Tae Heon Kim, Kyung Rae Kim, Jong-Min Lee, Dong Kyun Lee et al. Factors for maxillary sinus volume and craniofacial anatomical features in adults with chronic rhinosinusitis. Arch Otolaryngol Head and Neck Surgery 2010;136(6):610-15.

10. Maillet M, Bowler WR, Mc Clanahan SL, John MT, Ahmad M. Cone beam computed tomography evaluation of maxillary sinusitis. JOE 2011;37(6):753-757

11. Vchida Y, Katsuki T, Soejima Y. Measurement of maxillary sinus volume using computerized tomographic images. Int. J Oral Maxillofac Implants 1998;13:811-818

12. Alberti P W. Applied Surgical Anatomy of Maxillary Sinus. Otolaryngol Clin North Am 1976;9:3-20.

Source of Support: Nil, Confilict of Interst: None Declared 